\title{
RUPTURED SPLEEN.
}

\author{
By DUNCAN C. L. FITZWILLIAMS, M.D., Ch.M., F.R.C.S. \\ (Senior Surgeon, St. Mary's Hospital; Surgeon, Royal Masonic Hospital and \\ Mount Vernon Hospital.)
}

Most of the vital organs of the body such as the heart and lungs are protected by the cage of the thorax, others like the rectum, uterus, ovaries and bladder, are housed within the protective walls of the pelvis. Most of these organs are more or less fixed in position to allow them to function in a regular and rhythmic manner. The intestines being freely mobile and therefore less liable to injury are unprotected. But there are other organs which are slightly mobile and are semi-protected, among these are the liver, stomach, pancreas, and spleen.

Now the spleen is protected by the mobile 9th, Ioth and IIth ribs, the I2th rib is usually too short to be of any real use.

Injuries causing rupture of the spleen must be sudden and severe; they can be divided into three classes, namely falls, blows, and crushes.

Falls on the left side from any height may cause rupture of the spleen, though the height may not be great, if the left side encounters any obstruction, such as a rail, post or large stone which displaces the ribs forcibly inwards. I once saw a boy of I2 years old who had fallen off a railing along which he had been doing a balancing. walk, he had fallen across the top bar and had ruptured his spleen, splitting it practically in two.

Blows have to be severe and administered by a heavy implement over the region of the spleen. I remember attending a navvy, who in the course of a dispute with a comrade, was struck with the haft of a pick which ruptured the organ.

Crushes to the lower chest may easily rupture the spleen and the most common of these nowadays is the " knocked down and run over" accident by the light motor car. The wheels of a heavy car or lorry going over the middle of a person usually kills them outright or complicates matters by adding injuries of the liver, stomach, pancreas or intestines.

We are considering the normal spleen, of course, as we usually see it in this country. In malarial countries the organ may reach enormous proportions and stretch diagonally across the abdomen, where not only is it quite unprotected but is excessively friable and liable to injury at the slightest blow or push. Dwellers in the tropics are well aware of this fact which was the origin of the strict rules issued against striking native servants when such treatment of any underling was an almost universal practice.

No detailed mention need be made of those cases of rupture of the spleen from some slight injury or which may apparently occur spontaneously during the course of some other illness. These ruptures of the spleen have been reported in the course of almost every acute or infective disease ranging from endo-carditis, tuberculosis, to rare diseases such as anthrax. They have also been met with in many physiological conditions such as pregnancy and labour. Nor do we have to consider those curious cases which are met with from time to time where an apparently normal spleen ruptures spontaneously, or at all events for no apparent reason. 
We can suppose that the organ can be injured as the result of an injury which is not severe enough to cause actual rupture and that the injury may be recovered from in the usual way without causing any signs or symptoms. Graver forms of injury may cause slight bleeding of an intermittent nature, which becoming sealed off, the clot organises, adhesions form, and no ill effects follow. All bleeding must, I imagine, be rather intermittent, as the spleen slowly contracts and relaxes in a rhythmic manner.

The signs and symptoms of the more severe forms of accident are as a rule dramatically clear and distinct. First there is the history either of the patient or of someone who views the accident or occurrence, or of the policeman who accom. panies the case, which is always fairly definite though it may be only hearsay. There is usually some mark on the skin where the injury has been received.

Pain is variable and depends rather on the amount of local injury to the chest wall than to damage to the underlying spleen. Where the spleen is ruptured during the course of some concurrent disease, pain is seldom a help as it may be felt anywhere from the left shoulder to the right iliac fossa or to the left testis.

Injuries to the spleen in a case of fracture of the ribs are rare (probably on account of mobility of the ribs); and personally I have never seen it. A certain amount of rigidity will be present in the upper abdomen due to the local injury, and therefore may vary in amount, unless there is rupture of the stomach or intestines to complicate matters, in which case there will be board-like rigidity, calling for immediate exploration.

A sign, sometimes known as Balance's sign, is the persistence of dullness in the left hypochondrium when the patient is rolled over to the right. This is best noted where the rupture is small and the hæmorrhage is gradual, as in the case of many diseases. It is due to the fact that though the abdomen is full of fluid blood," which moves as the patient rolls over, the spleen itself is surrounded by a dense coagulum which does not move.

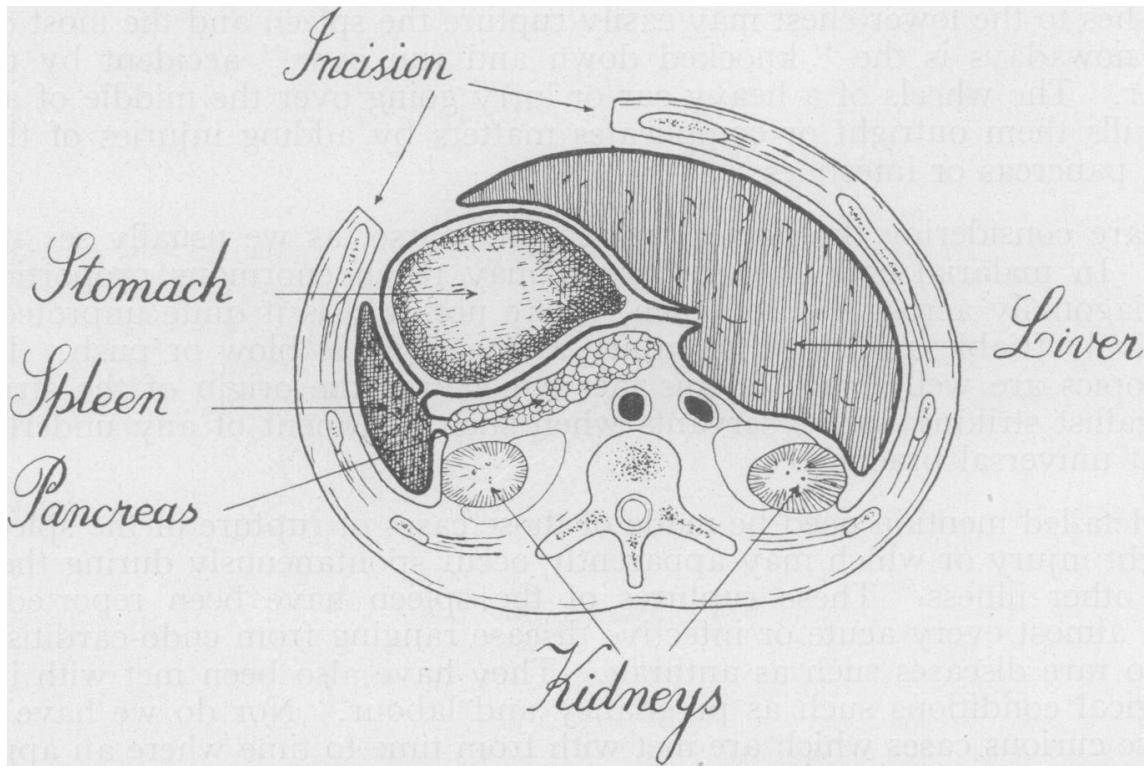

Cross section of the body at the level of the spleen. 
In most cases the symptoms and signs are completely overshadowed by the picture of shock, which is as a rule intense, and treatment must be directed to combat this, so as to allow the more localizing symptoms to appear. As the shock passes off the clinical picture takes on the hues of internal hæmorrhage, which gradually become unmistakable. In all cases therefore, where internal injuries are suspected, the pulse rate should be taken every ten or fifteen minutes and recorded; if bleeding is occurring, evidence will have established this by the end of two to three hours. The pulse rate rises steadily; its force, however, becomes weaker, pallor will have remained the same or even have become more marked, though shock should now be passing off. Later restlessness and air hunger may develop.

The diagnosis of where the damage is may not be easy, especially in crushes where damage may be done to the liver, pancreas, stomach, intestines, or even to the kidneys. The urine should always be examined as a routine precaution in these cases. If no diagnosis can be come to, and the clinical picture is one of internal hæmorrhage, there should be no delay, operation is called for and the cause of trouble must be sought.

Now as regards the incision, one has only to look up the literature on the subject of internal hæmorrhage from the spleen, to realise that almost every conceivable incision and mistake has been made. It is not uncommon to open below the umbilicus and find blood, and then jump to the conclusion that the injury is due to a rupture of the liver. A fresh incision is made in the tight hypochondrium, only to find the liver intact, and a third incision is needed to expose the damaged spleen; this with its accompanying loss of time and blood is to be avoided if possible. In my opinion, all cases of suspected internal hæmorrhage

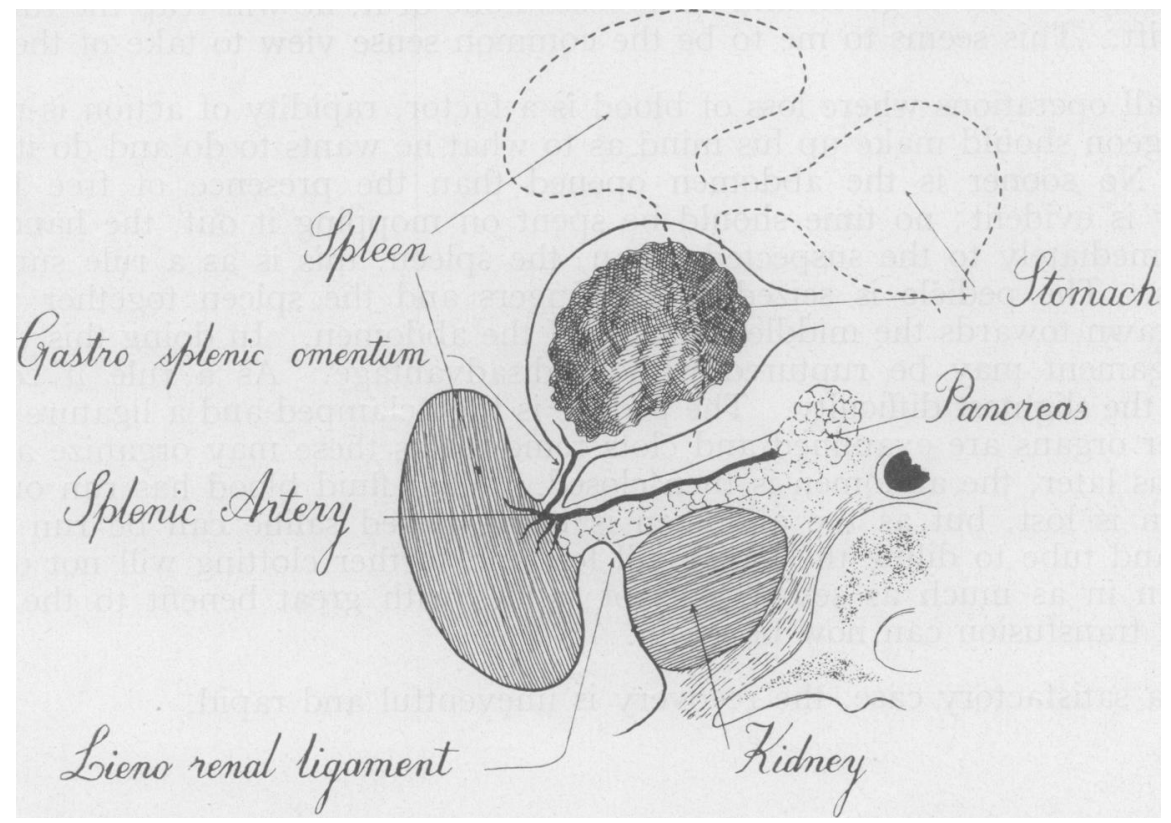

Illustration to show the spleen rotated forwards and to the right on the radius of the splenic artery, as it is drawn forwards, the lieno-renal ligament ruptures, if the injury has not already ruptured it. 
in the abdominal cavity, due to accidents, should be opened primarily above the umbilicus. In addition I do not favour the commonly made vertical incision, either in the mid-line or paramedian line, but strongly recommend one passing from the tip of the ninth costal cartilage to about one inch above the umbilicus. If the spleen is suspected, the incision is placed upon the left side, if the liver is suspected, it is placed upon the right side. This incision, I may add, is the one always used by myself for exposing the gall bladder; I know of no better one and it does the least damage to the neuro-muscular structure of the abdominal wall, and causes the least hæmorrhage. If necessary it can be prolonged right across the opposite side of the abdomen and the rib cartilages can be cut away if additional room is required. Hernia never foliows this incision. There is one incision which should always be avoided if the spleen is suspected, and that is one parallel with the rib margin on the left side.

The spleen can be made to rotate on an axis, the radius of which is the splenic artery and therefore the further forward it is drawn, the nearer the middle line it must go. The spleen cannot be pulled out sideways as the vessels cannot be prolonged.

Now a word about transfusions. It is now the common custom where operations have to be performed for the loss of blood, to give whole blood transfusions either before or during the operation in the hope that it will help the patient over the operation and diminish the shock of the proceeding. There is not the slightest doubt that fluids given at such times are of the greatest benefit, but it is not so much the quality as the quantity of fluid in the circulation which produces this effect, and to give real blood before the loss is stopped is a mere waste of good blood. If the patient must lose blood, as he will during the operation, then let him lose blood diluted with saline. Then when all chance of loss is paste the fresh blood can be given and as he loses none of it, he will reap the full benefit? of the gift. This seems to me to be the common sense view to take of the matter.

In all operations where loss of blood is a factor, rapidity of action is required. The surgeon should make up his mind as to what he wants to do and do it without delay. No sooner is the abdomen opened than the presence of free blood in quantity is evident; no time should be spent on mopping it out, the hand should pass immediately to the suspected organ, the spleen, this is as a rule surrounded by clots. The pedicle is seized in the fingers and the spleen together with the clots, drawn towards the middle line, out of the abdomen. In doing this the lienorenal ligament may be ruptured without disadvantage. As a rule it comes up without the slightest difficulty. The pedicle is then clamped and a ligature applied, the other organs are examined and clots removed as these may organize and form adhesions later, the abdomen is then closed. What fluid blood has run out of the abdomen is lost, but as the abdomen is being closed saline can be run in by a funnel and tube to dilute the blood still left and further clotting will not occur. I have run in as much as seven pints of saline, with great benefit to the patient. A blood transfusion can now be given.

In a satisfactory case, the recovery is uneventful and rapid. 